\title{
Teaching Benign Paroxysmal Positional Vertigo to Emergency Medicine Residents by Using Gagne's Nine Steps of Instructional Design
}

\author{
Khalid Bashir (D) ${ }^{1,2}$ \\ Lubna Rauf ${ }^{2}$ \\ Abdulla Yousuf ${ }^{\prime}$ \\ Shahzad Anjum (D) \\ Mohammed Talha Bashir ${ }^{3}$ \\ Amr Elmoheen (iD) ${ }^{1,2}$ \\ 'Department of Emergency Medicine, \\ Hamad General Hospital, Doha, Qatar; \\ ${ }^{2}$ College of Medicine, Qatar University, \\ Doha, Qatar; ${ }^{3}$ University of Aberdeen \\ School of Medicine and Dentistry, \\ Aberdeen, Scotland, UK
}

\begin{abstract}
Introduction: Patients commonly seek medical advice with dizziness symptoms. One of the common subtypes of dizziness is benign paroxysmal positional vertigo (BPPV). The American Academy of Neurology recommends that physicians should be trained in the physical maneuvers for the treatment of BPPV.

Methodology: The study participants were educated about BPPV using Gagne's instructional strategy. Before and after the education, three parameters were used for assessing their knowledge and skills about BPPV. Twenty MCQs for knowledge assessment and two skill stations, Dix-Hallpike test (DH) and canalith repositioning maneuver (CR) were used. An experienced emergency medicine (EM) faculty supervised the assessment.

Results: Nineteen EM residents participated in the study; mean age was 28.4 years $( \pm 1.7)$. Twelve $(63.15 \%)$ were male, and seven $(36.9 \%)$ were female. The median score before the course for the DH test was $2(1.7-3.0)$ and improved to 5(4.0-5.0). Similarly, CR's median score improved from $2(1.0-2.3)$ to $5(4.7-5.0)$. Both of these skills improved by $60 \%$. Preintervention MCQs mean score was 15.2 (14.4-16.1), which increased to 18.0 (17.4-18.6). MCQs improvement was recorded as $14 \%$.
\end{abstract}

Conclusion: The educational plan delivered by utilizing the Gagne's instructional design has resulted in significant improvement of the knowledge about BPPV.

Keywords: BPPV, Gagne instructional design, emergency department, residency teaching

\section{Introduction}

Benign Paroxysmal Positional Vertigo (BPPV) is a common medical condition in which patients suffer from spinning sensation after specific head movements. It is believed to be caused by free-floating calcium particles in the endolymph of the semicircular canals. ${ }^{1}$ The movement of these crystals sends anomalous signals to the brain, causing an illusion of movement. There are three semicircular canals (SCC), posterior, lateral, and anterior, each causing a different range of symptoms. Almost $85 \%$ of patients suffer from Posterior canal BPPV. BPPV can be reliably diagnosed with bedside tests to identify the location of the crystals within semicircular canals. One of the tests used to diagnose posterior canal BPPV is Dix Hallpike (DH), where the patient's head is brought to the edge of the bed from a sitting position. DH helps to identify the pathology in the left or right ear. BPPV is typically treated by numerous Canalith Repositioning (CR) maneuvers, which help move the crystals out of the semicircular canals. Despite being a common medical condition, patients usually suffer for a long time before getting appropriate help due
Correspondence: Lubna Rauf College of Medicine, Qatar University, P. O. Box: 27/3, Doha, Qatar Tel +974 4403787।

Email Lrauf@qu.edu.qa 
to a lack of physicians' knowledge and skills. ${ }^{2-4}$ The American Academy of Neurology and Head and Neck Surgery has recommended physicians' training in diagnosing and treating BPPV through physical maneuvers. ${ }^{1}$

Gagne's nine events of instruction were trialed to teach the DH maneuver to diagnose BPPV and CR to treat it to Emergency Medicine Residents (EMRs). It provides a robust roadmap to create an effective lesson plan. Gagne's theory is based on an information-processing model and describes several factors that influence learning, also called conditions of learning. These identify essential elements of a lesson that should be incorporated to facilitate better learning. The essential learning in each step is identified by doing a task analysis of the training. ${ }^{5,6}$ Gagne's nine events of instructional design provide general guidelines for the organization of a lesson. Gagne's instructional design distinguishes verbal information, intellectual skills, cognitive strategies, attitudes, and psychomotor skills to facilitate a learning plan in a stepwise manner. ${ }^{7}$

\section{Background}

BPPV topic was previously taught to the EMRs through a traditional face-to-face learning approach using PowerPoint slides and online videos with insignificant gain in the knowledge and skills. Teaching with slides for a long time was tedious and provided less opportunity for learners to participate in the discussion. ${ }^{8}$

The faculty got concerned about the lack of engagement from EMRs towards the teaching. They explored alternative approaches to enhance the educational experience and increase in knowledge and skills of EMRs in this crucial topic. There seemed to be an apparent disconnect between the teaching methods employed and the acquisition of learning objectives. Gagne pointed out that an intellectual skill cannot be learned by merely looking at the subject or provided to the learner through verbal communication. It must be learned, recalled, and put into use at a proper time to stick to the memory in a better way. ${ }^{9}$ Keeping that in mind, a colleague (KB), who was the program director of the fellowship program at the time of the study, proposed integrating Gagne's instructional design into the BPPV lesson plan as a solution to this. This instructional design model was chosen because it could be applied to a wide range of objectives or integrative objectives in complex learning. The first three steps involve the preparation of the students for learning. The next four steps are used to steer the actual learning process, whereas the final two steps mark the end of the event. ${ }^{7}$
Table 1 summarizes the nine events of instructions utilized during the lesson plan and delivery of the educational material related to BPPV management. As far as we know, no previous study has used Gagne's nine steps in teaching BPPV. The study aimed to assess the impact of teaching through Gagne's nine steps on the knowledge and skill enhancement on the subject of BPPV.

\section{Methodology}

The data was collected and analyzed during the EMRs training program's routine educational activities at Hamad General Hospital (HGH) in January 2018. Due to the study's educational nature, the IRB of Hamad Medical Corporation (16307) exempted the study from a formal review. $\mathrm{HGH}$ is the primary teaching hospital in the country and is one of the busiest emergency departments (ED) globally, where more than 450 thousand patients attend annually. The host hospital has a four-year residency program accredited by the graduate accreditation council of graduate medical education USA (ACGEM-I). The residents have weekly didactic teaching, which lasts approximately five hours. The study was completed on one of the teaching days. The participants were at different levels of training, and there were no exclusion criteria. The participants were assessed using the three measures $\mathrm{DH}$ test and were rated as zero (worst) through five (perfect). CR maneuvers were rated as zero (worst) through five (perfect). A twenty MCQs test (Appendix A) was prepared by an emergency physician with an otolaryngologist's help and was used to test the theoretical knowledge. The rating was standardized and tested for interrater reliability. The faculty supervising the process were senior EMR faculty who went through a calibration exercise on the rating. To reduce the bias same MCQs test was administered before and after the end of the educational session. The questions' results ranged from zero to twenty, and one score was given to each correct answer. The data collected was assessed by using the statistical package STATA.

Table I Basic Demographics

\begin{tabular}{|l|l|l|}
\hline No & Parameters & $\mathbf{N}=19$ \\
\hline 1 & Age (mean years) & $28.4 \pm 1.7$ \\
\hline 2 & Gender & \\
& Male & $12(63.15 \%)$ \\
& Female & $7(36.9 \%)$ \\
\hline 3 & Years in residency (mean years) & $2.5( \pm I .1)$ \\
\hline
\end{tabular}




\section{Results}

The characteristics of the 19 participants are shown in Table 2. The median score before the course for the DH test was $2(1.7-3.0)$ and improved to 5(4.0-5.0). Similarly, CR's median score improved from 2 (1.0 $2.3)$ to 5 (4.7-5.0). Both of these skills improved by $60 \%$. Pre-intervention MCQs mean score was 15.2 (14.4-16.1), which was increased to 18.0 (17.4-18.6). MCQs improvement was recorded as $14 \%$. Overall, there was a significant increase in the knowledge and skills of the EMRs following this approach of teaching DH maneuver and CR are summarized in Table 3.

\section{Discussion}

Our study has demonstrated that utilizing Gagne's nine events of instructions helped prepare a systematic, cohesive, and organized lesson plan that improved the knowledge and skills related to the management of BPPV among EMRs. The teaching day's learning activities were structured and aligned successfully with the nine steps of instruction's underpinning principles. It included gaining attention and enhancing learners' motivation, making the learning objectives explicit, stimulating recall of prior learning, presenting the content in a meaningful way, providing guidance, eliciting performance, providing

Table 2 Gagne's 9 Events of Instruction, Examples Used in the Teaching

\begin{tabular}{|c|c|c|}
\hline No & $\begin{array}{l}\text { Gagne's Event of } \\
\text { Instruction }\end{array}$ & Examples Used During the Teaching \\
\hline 1 & Gain attention & $\begin{array}{l}\text { Introduction of a case scenario, a } 55 \text {-year-old lady, brought into ED by the ambulance with a } 12 \text {-hour history of } \\
\text { severe vertigo, waking from the bed associated with nausea and vomiting, and every time she looks up, the room } \\
\text { starts spinning. How would you manage her? }\end{array}$ \\
\hline 2 & $\begin{array}{l}\text { Inform learners of } \\
\text { objectives }\end{array}$ & $\begin{array}{l}\text { EMRs were presented with the objectives of the lesson. After the session, you will be able to } \\
\text { I.Appreciate the pathophysiology of BPPV. } \\
\text { 2.Understand how to diagnose and treat BPPV within ED }\end{array}$ \\
\hline 3 & $\begin{array}{l}\text { Stimulate recall of prior } \\
\text { learning }\end{array}$ & $\begin{array}{l}\text { EMR was asked to share their experience of a case they have managed in the last } 12 \text { months. One student shared } \\
\text { his experience of managing but could not remember how all the steps were performed. }\end{array}$ \\
\hline 4 & Present stimulus & $\begin{array}{l}\text { The content was delivered for EMR to understand the pathophysiology, and how to diagnose and treat BPPV } \\
\text { through images and videos. }\end{array}$ \\
\hline 5 & $\begin{array}{l}\text { Provide learner } \\
\text { guidance }\end{array}$ & EMR were divided into groups of three or four where they explained and shown how to elicit the maneuvers \\
\hline 6 & Elicit performance & $\begin{array}{l}\text { EMR were divided into groups of three or four where they practiced the maneuver on simulated patient with the } \\
\text { direct supervision of trained faculty. }\end{array}$ \\
\hline 7 & Provide feedback & $\begin{array}{l}\text { EMR were given feedback within small groups by the experienced faculty on the diagnostic and therapeutic } \\
\text { maneuvers. }\end{array}$ \\
\hline 8 & Assess performance & $\begin{array}{l}\text { EMR had an MCQ assessment of } 20 \text { and skills assessment individually on simulated patients, and their skills } \\
\text { performance was graded from } 0 \text { to } 5\end{array}$ \\
\hline 9 & $\begin{array}{l}\text { Enhance retention and } \\
\text { transfer }\end{array}$ & $\begin{array}{l}\text { EMRs were given guidance to keep a logbook of the BPPV cases seen in real life and the patients' outcome. To be } \\
\text { discussed with their mentors in the next } 12 \text { months. }\end{array}$ \\
\hline
\end{tabular}

Table 3 Pre- and Post-Education Scores

\begin{tabular}{|l|l|l|l|l|}
\hline No & Assessment & Pre-Intervention Score & Post-Intervention Score & Improvement \\
\hline I & DH (median) & $2(1.7-3.0)$ & $5(4.0-5.0)$ & $60 \%$ \\
2 & CR (median) & 2 & $5(4.7-5.0)$ & $60 \%$ \\
3 & MCQ (mean) & $15.2(14.4-16.1)$ & $18.0(17.4-18.6)$ & $14 \%$ \\
\hline
\end{tabular}

Abbreviations: DH, Dix-Hallpike test, CR, canalith repositioning maneuver; MCQ, multiple choice question. 
feedback, assessing the performance, and enhancing retention and transfer. ${ }^{10}$ Post intervention assessment showed significant improvement in the performance of skills and MCQs score. It facilitated the learning process substantially and appeared to be better than the traditional lecturebased education.

During the small group skills teaching session, the faculty provided feedback using the Pendleton rules, a commonly used feedback method, ${ }^{11}$ in our hospital. In the Pendleton method of feedback, the learner first identifies his or her strong points. After that, the rest of the group remark on the observed strengths. Finally, the teaching faculty would comment about the strengths. In the second round, the learner is asked what went less well and what they would they do differently in the future. The group would also report their observations on areas that need improvement. In conclusion, the faculty mentions what could be done differently next time. ${ }^{6}$

In our study, the pre-intervention score increased from $2 / 5$ to $5 / 5$ in both the $\mathrm{DH}$ and CR procedure skills associated with the diagnosis and treatment of BPPV. There was a notable $60 \%$ increase in the performance of these skills. There was also a $14 \%$ increase in the knowledge comparing pre- and post-intervention MCQs test. Khadooji et al showed Gagne's 9 events of instruction to be very effective and helpful to design a lesson plan. They chose teaching of a practical procedure of insertion of peritoneal ascitic drain to junior doctors and devised steps of learning based on Gagne's nine events. They modified and combined couple of steps to suit their needs that enabled them to use it effectively in their teaching. ${ }^{6}$ Another study by Belfield showed the efficacy of this teaching method, when they used Gagne's nine steps to teach interpretation of a Chest X-Ray to the students. She found the steps to be quite adaptable and flexible. She learnt that they were equally useful for the students and the teachers. Students gave a very positive feedback as it addressed the learning aims and objectives very well and teachers felt that lessons were better organized and hence ran very smoothly. ${ }^{11} \mathrm{JY} \mathrm{Ng}$ strengthens the notion of Gagne's step being flexible and adaptable. In his study, they incorporated Gagne's steps into another teaching model to teach slit lamp use to the undergraduate medical students and found it very helpful to plan effective teaching sessions. ${ }^{12}$

Another similar study also confirmed improvement in bone marrow aspiration skills using Gagne's nine instructional steps. Small group teaching was used to teach and assess the clinical skills. The employment of this approach was very successful in achieving the objectives. Other studies have also recommended the use of small-group education. $^{13,14}$

\section{Limitations}

Several limitations are needed to be considered concerning this study. Firstly, simulated patients (SPs) were involved in learning about BPPV. Using SPs helps acquire the skills, but these healthy individuals will not have any positive BPPV signs, so DH maneuver and CR procedures would have hypothetical outcomes. Utilizing real patients for this type of teaching is unachievable due to the teaching session's planned nature and the unpredictable flow of patients in the ED who might have this problem. They would also need consent and monitoring, which can make the whole process very complicated and time-consuming. Therefore, using SPs was the only practical approach. EMRs have been asked to keep a logbook of real-time patients presenting with this condition and have been advised to follow them up with their mentors to discuss the implementation of their newly acquired skills and their outcomes.

Secondly, this pedagogical approach requiring small group learning requiring many skilled facilitators and additional space to practice the skills in small groups. We had to find numerous rooms to facilitate the small group teaching and spent several hours training the faculty to avoid interrater reliability. Due to this, it may not be possible for every emergency department to follow this approach.

Thirdly, the training was completed in only one hospital and the sample may not be representative of the other sites; hence, the results may not be generalizable. However, the EMRs completed their four years of training within the host hospital; therefore, for this purpose, only local enrollment was done.

\section{Conclusion}

The learning plan delivered based on Gagne's instructional method has increased students understanding of the BPPV significantly and engaged them actively in the learning process.

\section{Acknowledgment}

Open Access funding provided by the Qatar National Library. 


\section{Disclosure}

The authors report no conflicts of interest in this work.

\section{References}

1. Pérez-Vázquez P, Franco-Gutiérrez V, Soto-Varela A, et al. Practice guidelines for the diagnosis and management of benign paroxysmal positional vertigo otoneurology committee of Spanish otorhinolaryngology and head and neck surgery consensus document. Acta Otorrinolaringol. 2018;69(6):345-366. PMID: 28826856. doi:10.1016/j.otorri.2017.05.001

2. Bashir K, Qotb MA, Alkahky S, Fathi AM, Mohamed MA, Cameron PA. Are emergency physicians and paramedics providing canalith repositioning manoeuvre for benign paroxysmal positional vertigo? Emerg Med Australas. 2015;27(2). doi:10.1111/17426723.12362

3. Bashir K, Pathan S, Farook S, Khalid MM, Zayed S. Disconnect between available literature and clinical practice: exploring gaps in the management of t-BPPV in the emergency department. J Emerg Med Trauma Acute Care. 2017;2017(1). doi:10.5339/jemtac.2017.6

4. Bashir K, Alessai GS, Salem WA, Irfan FB, Cameron PA. Physical maneuvers: effective but underutilized treatment of benign paroxysmal positional vertigo in the ED. Am J Emerg Med. 2014;32(1):95-96. doi:10.1016/j.ajem.2013.10.012

5. Buscombe C. Using Gagne's theory to teach procedural skills. Clin Teach. 2013;10(5):302-307. doi:10.1111/tct.12051

6. Khadjooi K, Rostami K, Ishaq S. How to use Gagne's model of instructional design in teaching psychomotor skills. Gastroenterol Hepatol Bed Bench. 2011;4:116.
7. Merrienboer J. Instructional design. In: Dent J, Harden R, editors. A Practical Guide to Medical Teachers. Churchil, Livingstone: Elsevier; 2013:200-204.

8. Neo TK, Neo M, Teoh BSP. Assessing the effects of using gagne's events of instructions in a multimedia student-centred environment: a Malaysian experience. Turkish Online J Distance Educ. 2010;11 (1):20-34. doi:10.17718/tojde.52804

9. Woo WH. Using Gagne's instructional model in phlebotomy education. Adv Med Educ Pract. 2016;7:511-516. PMID: 27621681; PMCID: PMC5012615. doi:10.2147/AMEP.S110357

10. Chen JJ, Johannesmeyer HJ. Gagné's 9 events of instruction with active learning: teaching student pharmacists how to measure blood pressure. J Pharm Pract. 2019:897190019875610. PMID: 31526081. doi:10.1177/0897190019875610

11. Belfield J. Using Gagne's theory to teach chest X-ray interpretation. Clin Teach. 2010;7(1):5-8. PMID: 21134135. doi:10.1111/j.1743498X.2009.00329.x

12. Ng JY. Combining Peyton's four-step approach and Gagne's instructional model in teaching slit-lamp examination. Perspect Med Educ. 2014;3(6):480-485. PMID: 25294337; PMCID: PMC4263794. doi:10.1007/s40037-014-0136-x

13. Lemoine ER, Rana J, Burgin S. Teaching \& Learning Tips 7: smallgroup discussion. Int $J$ Dermatol. 2018;57(5):583-586. PMID: 29633254. doi:10.1111/ijd.13706

14. Van Diggele C, Burgess A, Mellis C. Planning, preparing and structuring a small group teaching session. BMC Med Educ. 2020;20(S2). doi:10.1186/s12909-020-02281-4
Advances in Medical Education and Practice

\section{Publish your work in this journal}

Advances in Medical Education and Practice is an international, peerreviewed, open access journal that aims to present and publish research on Medical Education covering medical, dental, nursing and allied health care professional education. The journal covers undergraduate education, postgraduate training and continuing medical education

\section{Dovepress}

including emerging trends and innovative models linking education, research, and health care services. The manuscript management system is completely online and includes a very quick and fair peer-review system. Visit http://www.dovepress.com/testimonials.php to read real quotes from published authors. 